\title{
Cimentos Portland aditivados com arenito zeolítico com propriedades pozolânicas
}

\section{Portland cements activated with pozzolanic zeolitic sandstone}

\author{
Marcelo de Souza Picanço ${ }^{1}$, Rômulo Simões Angélica ${ }^{2}$, \\ Márcio Santos Barata ${ }^{3}$
}

\author{
1,2,3 Universidade Federal do Pará, Instituto de Geociências, Laboratório de Caracterização Mineral - LCM - Av. Augusto \\ Correa, 1, Guamá, 66075-110, Belém, Pará. \\ e-mail: marcelopicanco2004@yahoo.com.br; angelica@ufpa.br; marciosbarata@yahoo.com.br
}

\section{RESUMO}

O uso adequado de pozolanas possibilita a produção de cimentos especiais, de menor custo de fabricação e de maior durabilidade que os correspondentes sem adição. $\mathrm{O}$ emprego dessas adições minerais possibilita ganhos significativos em termos de produtividade e uma extensão da vida útil dos equipamentos de produção e da própria jazida de calcário, também ajudando na diminuição de $\mathrm{CO} 2$ lançado na atmosfera.

As zeólitas têm sido utilizadas como material pozolânico em misturas com "terras vulcânicas" e água nas construções desde o tempo do antigo Império Romano. Nos dias atuais, existem muitas discussões envolvendo reatividade pozolânica das zeólitas naturais na incorporação dos cimentos Portland.

Na Região nordeste do Brasil, zeólitas sedimentares relacionadas a arenitos da Bacia do Parnaíba foram descobertas pelo Serviço Geológico do Brasil nos anos 2000. Estes arenitos são constituídos em sua maioria de quartzo, zeólitas naturais (estilbita) e argilominerais (esmectita). Estudos preliminares constataram que este arenito pode ser empregado como material pozolânico em sistemas a base de cimento Portland, desde que o material seja peneirado para remoção do quartzo e ativado termicamente, uma vez que a estilbita é uma zeólita de baixa atividade pozolânica.

O objetivo geral desse trabalho foi determinar qual proporção de arenito zeolítico ativado termicamente proporciona melhores propriedades mineralógicas e mecânicas ao cimento Portland.

No programa experimental empregou-se o arenito zeolítico passante na peneira 200\# e calcinado à temperatura de $500^{\circ} \mathrm{C}$. A análise química das amostras foi realizada por espectroscopia de fluorescência de raios-x e a caracterização mineralógica por difração de raios-x e análise termogravimétrica e termodiferencial. O comportamento da hidratação dos cimentos foi avaliado através de calorimetria de condução, difratometria de raio-X e análises termodiferencial e termogravimétricas. Para avaliação da atividade pozolânica foi adotado um ensaio mecânico de resistência à compressão em argamassas cimento Portland (CP I -S) e areia, com percentuais de substituição de cimento por arenito de 10, 20 e $30 \%$.

Os resultados mostraram que o arenito zeolítico calcinado com a percentual de substituição de $10 \%$ proporcionou às argamassas melhor resultado tem termos de resistência à compressão simples, contudo estudos mais aprofundados de durabilidade e a idades mais avançadas podem indicar que teores mais elevados do arenito zeolítico podem também ser apropriados para a produção de concretos, principalmente em obras de infraestrutura como barragens, canais, entre outras.

Palavras-chave: pozolana, cimento Portland, arenito, zeólita, estilbita.

\section{ABSTRACT}

The proper use of pozzolans enables the production of special cements with lower manufacturing cost and higher durability in comparison with cements without mineral additions. It also enables significant gains in productivity and in equipment service life in the factory as well as reduce the $\mathrm{CO} 2$ emission into the atmos- 
phere.

Zeolites have been used as pozzolanic material in mixtures with Fuller's Earth and water in buildings from the ancient Roman Empire. Nowadays, there are many discussions involving pozzolanic reactivity of natural zeolites in the incorporation to Portland cement.

In the Northeastern region of Brazil, sedimentary zeolites related to sandstones of the Parnaiba Basin were discovered by the Geological Survey of Brazil in the 2000s. These sandstones are mainly composed by quartz, natural zeolites (estilbity) and clay (smectite). Preliminary studies have pointed that this sandstone may be used as pozzolanic material in Portland cements. The material must be previously grinded to remove quartz and thermally activated, since stilbite is a zeolite with low pozzolanic activity.

The aim of this study was to evaluate the ideal amount of thermally activated zeolitic sandstone to be incorporated in the Portland cement in order to improve its mechanical and mineralogical properties.

In the laboratory, the $<\# 200$ fraction of the zeolitic sandstone was calcined at $500^{\circ} \mathrm{C}$. Chemical and mineralogical analysis were carried out by X-ray fluorescence spectroscopy (XRF) and X-ray Diffractometry (XRD), respectively. The hydration behavior of the cements was evaluated using heat-flow calorimetry, besides thermal analysis and XRD. To evaluate the physical properties, mechanical testing of compressive strength in cement mortar Portland with different proportions of sandstone was carried out.

The results showed that the AZ2-3 zeolitic sandstone with the proportion of $10 \%$ incorporated in Portland cement type CPI-S, showed the best result of compressive strength and mineralogical properties of the samples suitable for the production of CPII-Z type commercial cement.

Keywords: pozzolan, Portland cement, limestone, zeolite, stilbite.

\section{INTRODUÇÃO}

O objetivo atual da indústria de cimento Portland é produzir aglomerantes com baixo custo de produção energética, com menor emissão de $\mathrm{CO} 2$ para a atmosfera e que ao mesmo tempo sejam capazes de proporcionar maior durabilidade aos concretos e argamassas. Dentro deste panorama, uma das alternativas para se alcançar os objetivos supramencionados seria o emprego de adições minerais reativas com vistas a produção de cimentos Portland compostos. Uma das adições minerais mais utilizadas são as pozolanas.

A pozolana é definida como um material silicoso ou sílico-aluminoso que por si só não possui propriedade aglomerante, diferentemente da escória de alto forno, que é um material cimentício. No entanto, a pozolana, em uma forma finamente dividida e na presença de umidade, reage quimicamente com hidróxido de cálcio a temperatura ambiente para formar um produto estável em água, os silicatos de cálcio hidratados (C-S-H) [1] .

As principais vantagens da incorporação de pozolanas em cimento Portland é o aumento da resistência mecânica, a redução da permeabilidade à água e consequentemente aos agentes agressivos como íons cloretos e sulfatos, redução da reação álcali-agregado e diminuição do calor de hidratação [2]].

Alguns tipos de zeólitas possuem propriedades pozolânicas e por isto possuem potencial para serem incorporadas na produção do cimento Portland. São interessantes do ponto de vista econômico, pois se enquadram em todas as vantagens já relatadas, principalmente quando de ocorrência natural, uma vez que não necessitam de tratamento térmico ou incipiente (baixas temperaturas de queima) para adquirirem propriedades pozolânicas []].

As zeólitas são silicatos de alumínio hidratados com estruturas (interna e externa) em forma de gaiolas que se caracterizam por apresentarem áreas superficiais especificas bastante elevadas. Estas áreas de superfície elevadas são responsáveis pela alta reatividade da mesma [3]. O tipo de zeólitas natural mais abundante e de ampla aplicação industrial é a "heulandita", com uma relação de $\mathrm{Si} / \mathrm{Al}$ que varia de 3 a 5 e com uma composição química igual a (Na, K)Ca4(A19Si27O72).24H2O. No entanto existe também a Clinoptilolita ou "sílica elevada" de heulandita, com composição igual a (Na, K)6 Al6(Si30O72). 20 H2O. A heulandita é definida como um mineral de relação $\mathrm{Si} / \mathrm{Al}<4$ quando a clinoptilolita tiver uma relação $\mathrm{Si} / \mathrm{Al}>4$. Ambos são minerais classificados no sistema monoclínico seguido do grupo cristalino do tipo $\mathrm{C} 2 / \mathrm{m}$.

No Brasil, até o momento não existem depósitos naturais de zeólitas conhecidos que possam ser explorados comercialmente para fabricação de cimento Portland ou para qualquer outra atividade industrial. Contudo, foi descoberta nos anos 1990 na Bacia do Parnaíba, uma ocorrência de zeólita sedimentar, do tipo predominantemente estilbita, associada a arenitos pertencentes à formação corda [4]. Preliminarmente, através da técnica de condutividade elétrica, para efeito de comparação com outro material, foram feitos estudos sobre a atividade pozolânica desse arenito. Concluiu-se que a estilbita da Bacia do Parnaíba possui baixa ati- 
PICANÇO, M.S.; ANGÉLICA, R.S.; BARATA, M.S. revista Matéria, v.19, n.02, pp. 68-80, 2014.

vidade pozolânica em razão da sua composição química, alto teor de quartzo e a presença do Ca2+, que reduz a capacidade de troca catiônica []․

Outros dois trabalhos mais completos e exclusivos sobre a identificação e beneficiamento desse arenito foi realizado recentemente no Brasil. Os resultados mostraram que o arenito da Bacia do Parnaíba, quando peneirado e calcinado apresenta atividade pozolânica devido à presença da estilbita e esmectita. Contudo, para atender aos critérios de produção do cimento é necessário cominuir e peneirar o arenito de modo que passe nas peneiras 200 (abertura 75 micra) e 325 (abertura 45 micra) e em seguida ativá-lo termicamente à temperatura de $500^{\circ} \mathrm{C}$. O peneiramento teve como função separar os minerais potencialmente pozolânico (estilbita e a esmectita) do mineral inerte, no caso o quartzo. O tratamento térmico objetivou incrementar a atividade pozolânica, pois ocasiona o desordenamento parcial das estruturas cristalinas tanto da estilbita quanto da esmectita [] ] e []]. Nestes estudos experimentais foram produzidos dois tipos de pozolanas, uma proveniente do material passante na peneira 200 e a outra passante na peneira 325, sendo que ambas foram calcinadas a temperatura de $500^{\circ} \mathrm{C}$. A diferença entre essas duas pozolanas é a quantidade aproveitável de material em relação ao arenito não beneficiado. O percentual de aproveitamento do material passante na peneira 200 fica entre 15 e $17 \%$ enquanto que o do passante na peneira 325 foi de apenas $2 \%$.

A exceção dos trabalhos experimentais anteriormente citados []][7], até o presente momento não foi encontrado na bibliografia nenhum trabalho científico que aborde a questão da atividade pozolânica de arenitos com a presença de zeólitas do tipo estilbita. Identificou-se apenas um trabalho realizado por MONTANHEIRO [ [ ] que estudou a potencialidade pozolânica de arenitos opalinos da serra do Itaqueri, em São Paulo. Os resultados mostraram que o aglomerante natural de sílica intersticial presente nestes arenitos (calcedônia e opalina) proporcionou-lhe alta atividade pozolânica com cimento Portland, na ordem de 75 e $90 \%$.

Os dois trabalhos desenvolvidos para estudo dos arenitos com estilbita fazem parte de um projeto de pesquisa mais amplo conduzido pelo Grupo de Mineralogia Aplicada do Instituto de Geociências da Universidade Federal do Pará, que visa encontrar uma aplicabilidade industrial a estas zeólitas sedimentares que já foram amplamente estudadas e caracterizadas do ponto de vista geológico, mas não do tecnológico. Estes depósitos possuem grande potencial de aplicação em termos de logística devido à proximidade a várias fábricas de cimento Portland localizadas no sudeste do Estado do Pará, sudoeste do Maranhão e norte do Tocantins. Esta região não dispõe de depósitos de pozolanas naturais para fabricação de cimento Portland pozolânico, o que induz as fábricas a produzir cimentos Portland sem a incorporação de adições minerais, que em termos da qualidade do produto não é favorável, além de elevar em demasia o custo energético e aumentar a emissão de CO2 para a atmosfera.

O presente trabalho constitui-se em um terceiro passo deste programa experimental mais amplo, no qual objetiva avaliar a influência de diversos percentuais de substituição do arenito beneficiado ao cimento Portland sobre a resistência à compressão e a durabilidade para uma possível produção em escala industrial.

\section{MATERIAIS E MÉTODO}

A amostra de partida consistiu de arenito zeolítico da Bacia do Paraíba, pertencente à Formação Corda, coletada nas proximidades da cidade de Imperatriz, sul do Maranhão. Todos os detalhes do contexto geológico desse arenito, da amostragem, preparação da amostra e a caracterização química e mineralógica foram apresentados pelos autores em PICANÇO [] . A partir dos resultados obtidos pelos autores em [] , selecionou-se apenas a amostra do arenito passante na peneira 200 (AZ2), não ativado termicamente. Os detalhes das justificativas, caracterização e resultados das análises dessas amostras são apresentados em [7].

A pozolana produzida neste trabalho foi proveniente da calcinação da amostra (AZ2) à temperatura de $500^{\circ} \mathrm{C}(\mathrm{AZ2}-3)$ [6] [7]. O procedimento de produção da pozolana consistiu da secagem da amostra AZ2 até a constância de massa em estufa a $95^{\circ} \mathrm{C}$. Em seguida, $400 \mathrm{~g}$ da amostra seca de arenito foram submetidas à calcinação durante 4 horas na temperatura específica. Logo após, a amostra de arenito peneirada e calcinada foi cominuída em moinho de bolas.

A caracterização química, física e mineralógica do arenito zeolítico peneirado, calcinado e moído (AZ2-3) foi realizada por meio de espectroscopia de fluorescência de raios-x (FRX), análise termogravimétrica (ATG) e termodiferencial (ATD) e granulometria por difração a laser. A identificação das fases hidratadas formadas nas pastas de cimento Portland foi determinada por difração de raios-X (DRX). A reatividade pozolânica foi avaliada por três métodos: por calorimetria de condução, por análise termogravimétrica (ATG) para determinação do teor de hidróxido de cálcio consumido e pela resistência à compressão de argamassas de cimento Portland. O cimento empregado foi o isento de adições minerais ativas e com menor teor de incorporação, o CP I S, sendo constituído por $95 \%$ de clínquer e $5 \%$ de gesso e pó-de-calcário. 
PICANÇO, M.S.; ANGÉLICA, R.S.; BARATA, M.S. revista Matéria, v.19, n.02, pp. 68-80, 2014.

Para as análises químicas por FRX foi utilizado o espectrômetro modelo Axios-Minerals, da PANALYTICAL, com tubo de raios X cerâmico, anodo de ródio (Rh) com máximo nível de potência $2,4 \mathrm{KW}$. As análises foram feitas em pastilhas fundidas (elementos maiores), com a utilização de cerca de $1 \mathrm{~g}$ de amostra pulverizada, misturada a $8 \mathrm{~g}$ de fundente tetraborato de lítio (Li2B4O7). Essa mistura é previamente submetida à homogeneização para melhor agregar a amostra. Em seguida, a mistura foi fundida a aproximadamente $1200^{\circ} \mathrm{C}$ em cadinho de platina. Os elementos traços foram analisados em pastilha prensada. Os dados foram adquiridos através do software SuperQ Manager e o tratamento dos dados foi realizado pelo software IQ+, ambos da PANALYTICAL.

Para as análises térmicas (ATD-ATG) foi empregado um equipamento modelo PL Thermal Science com analisador térmico simultâneo STA1000/1500, da StantonRedcroft Ltda. O equipamento possui um forno cilíndrico vertical e conversor digital acoplado a um microcomputador, utilizando uma faixa de temperatura entre o ambiente e $1100^{\circ} \mathrm{C}$, com taxa de aquecimento de 5 a $20^{\circ} \mathrm{C} / \mathrm{min}$ e alumina calcinada como referência. Neste programa experimental foram realizadas dois tipos de análises com este equipamento. A primeira com vistas a identificar os minerais constituintes do arenito apenas peneirado (AZ2) e peneirado, calcinado e moído (AZ2-3). A segunda análise objetivou determinar a quantidade de portlandita consumida pela pozolana, no caso o AZ2-3, através da identificação da área do pico correspondente a desidroxilação da portlandita (ATD). Levou-se em conta nesta análise, para efeito de cálculo da portlandita efetivamente consumida pela pozolana, o percentual da diluição atribuída aos percentuais de substituição do cimento Portland pela pozolana. Neste caso, comparou-se para cada pasta analisada, com ou sem arenito, as áreas dos picos correspondentes a desidroxilação da portlandita determinadas nas curvas de ATD com as áreas teóricas correspondentes a substituição do cimento Portland por adições, de modo a determinar o efeito de diluição que a quantidade a menor de cimento Portland reflete na geração de portlandita. Foram confeccionadas 04 (quatro) pastas, uma de referência, apenas com cimento Portland e água, e as demais com percentuais de substituição de cimento pelo arenito pozolânico (AZ2-3) de 10, 20 e 30\%. A relação água/aglomerante empregada foi 0,50 e a idade analisada para avaliação do consumo de portlandita foi aos 7 dias de hidratação. As pastas, logo após a moldagem em cadinhos de aço, foram lacradas e armazenadas em dessecadores de vidro, isentos de gás carbônico. A taxa de calcinação adotada foi de $10^{\circ} \mathrm{C} /$ minuto.

Na DRX foi empregado o método do pó. As análises foram realizadas em difratômetro modelo X'PERT PRO MPD (PW 3040/60) da PANALYTICAL, com goniômetro PW3050/60 ( $\theta / \theta$ ), tubo de raios X cerâmico com anodo de $\mathrm{Cu}(\mathrm{K} \alpha 1=1,789 \AA)$, modelo PW3373/00, foco fino longo (2200 W- $60 \mathrm{kV})$, filtro K $\beta$ de Ni. As condições instrumentais utilizadas foram: varredura de 5 a $70^{\circ} \mathrm{em} 2 \theta$, voltagem de $40 \mathrm{kV}$ e corrente de $40 \mathrm{~mA}$, tamanho do passo $0,02^{\circ}$ em $2 \theta$ e tempo/passo de $60 \mathrm{~s}$, fenda divergente de $1 / 8^{\circ}$ e antiespalhamento de $1 / 4^{\circ}$; máscara de $10 \mathrm{~mm}$; amostra em movimentação circular com frequência de 1 rotação/s. As mesmas amostras de arenito e pastas de cimento Portland confeccionadas para a análise térmica foram submetidas a DRX. A identificação das fases é feita através do Software High Score Plus, também da Panalytical, por comparação do padrão difratométrico com fichas/padrões do Banco de Dados do ICDD-PDF (Internacional Center for Diffraction Data, Powder Diffraction File).

$\mathrm{Na}$ análise da calorimetria de condução foi empregado um microcalorímetro isotermal que se fundamenta no princípio da condução de calor. O fluxo de calor produzido durante as reações de hidratação passa por termopares especiais, constituídos por 71 elementos semicondutores de BiTe, conectados em série. A mudança na temperatura, causada pela evolução do calor durante a hidratação, excita os semicondutores, resultando em uma voltagem, medida por um multímetro digital. Os dados adquiridos em nV ou $\mu \mathrm{V}$ são gravados instantaneamente por um computador e são convertidos para unidades de fluxo de calor através da calibração do equipamento ( $\mathrm{mW} / \mathrm{g})$. Os ruídos são reduzidos significativamente através da ligação de termopares em polos opostos, sendo um termopar para a amostra e outro para uma referência inerte (alumina pulverizada), que possui a mesma capacidade térmica do material da amostra. O equipamento possui quatro portasamostra, sendo um para a referência (alumina pulverizada) e os demais para as pastas em análise. Como referencia utilizou-se uma mistura de $2 \mathrm{~g}$ de água com $2 \mathrm{~g}$ de óxido de alumínio (Al2O3) e cadinhos de aço nas seguintes características: quantidade de amostra em cada cadinho $4 \mathrm{~g}$ ( $2 \mathrm{~g}$ de amostra e $2 \mathrm{~g}$ de água), constante de tempo: $50 \mathrm{seg}$, sensibilidade a $25^{\circ} \mathrm{C}: 98 \mu \mathrm{V} / \mathrm{mW}$ e resolução de $2 \mu \mathrm{W}$. Foram analisadas 04 (quatro) pastas de cimento Portland, a primeira constituída apenas com cimento Portland CPI-S e água e as demais com 10, 20 e $30 \%$ de substituição do cimento Portland pelo arenito zeolítico AZ2-3. A relação água/aglomerante (cimento + adição mineral) das pastas foi 1,00 e o cimento empregado, no caso o CPI-S, é isento de adições minerais ativas, sendo constituído por $95 \%$ de clínquer e $5 \%$ de gesso e outras adições inertes.

Todos os equipamentos anteriormente descritos pertencem ao Laboratório de Caracterização Mineral (LCM) do Instituto de Geociências da Universidade Federal do Pará. 
PICANÇO, M.S.; ANGÉLICA, R.S.; BARATA, M.S. revista Matéria, v.19, n.02, pp. 68-80, 2014.

Para determinação da distribuição granulométrica das partículas do arenito zeolítico AZ2-3 foi utilizado o equipamento ANALYSETTE 22 MICROTEC PLUS ANALISADOR DE PARTÍCULAS A LASER, que emprega o Método Fourier Invertido com Amplitude de Leitura 0,08 $\mu \mathrm{m}$ a $2.000 \mu \mathrm{m}$. Este equipamento pertence ao Laboratório de Mineralogia e Geoquímica Aplicada - LMGA/ UFPA.

Para o ensaio mecânico em argamassas com cimento Portland (CPI-S) foram confeccionadas 04 (quatro) argamassas com traço em massa de 1:3 (cimento : areia) e fator água/aglomerante de 0,55. A primeira argamassa, de referência, utiliza apenas cimento, areia normal do IPT e água, enquanto que para as demais argamassas, parte da massa de cimento (10, 20 e 30\%) fora substituída pelo arenito zeolítico AZ2-3. Para cada argamassa foram moldados seis corpos de provas de $50 \mathrm{~mm}$ de diâmetro e $100 \mathrm{~mm}$ de altura, sendo três para a idade de 7 dias e os demais para 28 dias.

\section{RESULTADOS E DISCUSSÕES}

\subsection{Caracterização do Arenito Zeolítico}

3.1.1 Análise química e física dos arenitos zeolíticos

Os resultados obtidos nas análises químicas das amostras do Arenito zeolítico AZ2 (arenito peneirado e não calcinado) e AZ2-3 (arenito peneirado, calcinado e moído) estão apresentados na Tabela 1, sendo a análise da primeira amostra já caracterizada e apresentada por []].

Tabela 1: Análise química.

\begin{tabular}{|c|c|c|}
\hline Elementos Maiores (\%) & $\mathbf{A Z 2}$ & AZ2-3 \\
\hline $\mathrm{SiO}_{2}$ & 55,97 & 63,93 \\
\hline $\mathrm{Al}_{2} \mathrm{O}_{3}$ & 13,50 & 15,17 \\
\hline $\mathrm{Fe}_{2} \mathrm{O}_{3}$ & 3,92 & 4,50 \\
\hline $\mathrm{TiO}_{2}$ & 0,49 & 0,50 \\
\hline $\mathrm{CaO}$ & 5,36 & 5,93 \\
\hline $\mathrm{MgO}$ & 2,95 & 3,45 \\
\hline $\mathrm{Na}_{2} \mathrm{O}$ & 0,15 & 0,20 \\
\hline $\mathrm{K}_{2} \mathrm{O}$ & 1,14 & 1,40 \\
\hline Álcalis disponíveis em $\mathrm{Na}_{2} \mathrm{O}$ & 0,90 & 1,12 \\
\hline $\mathrm{Cr}_{2} \mathrm{O}_{3}$ & $<0,10$ & $<0,10$ \\
\hline $\mathrm{MnO}$ & 0,12 & 0,11 \\
\hline $\mathrm{P}_{2} \mathrm{O}_{5}$ & 0,16 & 0,18 \\
\hline $\mathrm{SO}_{3}$ & 0,28 & 0,26 \\
\hline $\mathrm{BaO}$ & 0,25 & 0,25 \\
\hline $\mathrm{SrO}$ & 0,44 & 0,41 \\
\hline P.F. & 15,19 & 3,64 \\
\hline $\mathrm{SiO}_{2} / \mathrm{Al}_{2} \mathrm{O}_{3}$ & 4,14 & 4,21 \\
\hline Total & 100,01 & 100,03 \\
\hline
\end{tabular}

Observação:

${ }^{1}$ Análise química realizada por MEV - EDS

A composição química do arenito in natura, não calcinado, mas sim apenas peneirado (AZ2), é muito semelhante aos resultados apresentados por outros pesquisadores que estudaram o mesmo arenito zeolitico e caracterizaram quimicamente a estilbita presente através de análise por microssonda [9]. Na amostra não calcinada os percentuais de $\mathrm{SiO} 2, \mathrm{Al} 2 \mathrm{O} 3$ e de perda ao fogo estão muito próximos aos valores da zeólita pura. A relação $\mathrm{Si} / \mathrm{Al}$ de 4,14 enquadra-se no intervalo de 2,50 a 5,00 atribuído a estilbita na classificação de Meier [10]. O teor de $\mathrm{Fe} 2 \mathrm{O} 3$ de 3,92\% está relacionado à goethita. $\mathrm{O}$ percentual de $\mathrm{CaO}$ de 5,36\% está associado a estrutura da estilbita, sendo notório o domínio do $\mathrm{CaO}$ em detrimento do $\mathrm{Na} 2 \mathrm{O}(0,15 \%)$ e $\mathrm{K} 2 \mathrm{O}(1,14 \%)$.

$\mathrm{Na}$ amostra calcinada do arenito, AZ2-3, ocorre o aumento nas concentrações dos óxidos em função da perda de massa referente à remoção da água de constituição da estrutura cristalina da estilbita e, em menor proporção, da perda das hidroxilas da esmectita. Dentro dos padrões de requisitos químicos estabelecidos pela NBR 12653 [12], o arenito zeolítico calcinado atende a todos estes parâmetros. A soma dos percentuais de $\mathrm{SiO} 2$, $\mathrm{Al} 2 \mathrm{O} 3$ e $\mathrm{Fe} 2 \mathrm{O} 3$ é superior a $70 \%$. O teor de $\mathrm{SO} 3$, de $0,26 \%$, é bastante inferior ao limite máximo de 5\%. A 
PICANÇO, M.S.; ANGÉLICA, R.S.; BARATA, M.S. revista Matéria, v.19, n.02, pp. 68-80, 2014.

perda ao fogo de 3,64 é inferior ao máximo de 6\%. O percentual de equivalente alcalino em Na2O é de $1,12 \%$, inferior ao limite máximo estipulado em 1,5\%. Além do mais, os álcalis presentes no arenito zeolítico estão presentes na forma de álcalis insolúveis em água, dentro da estrutura da zeólita.

Com relação às características físicas das amostras, destaca-se que o arenito calcinado e submetido à moagem apresentou uma granulometria mais fina que a do cimento Portland empregado na pesquisa, com diâmetro médio (D50) de 32 $\mu \mathrm{m}$ enquanto que D50 do cimento Portland CPI-S é de $65 \mu \mathrm{m}$. A Figura 1 mostra a distribuição granulométrica das partículas do arenito zeolítico calcinado (AZ2-3).

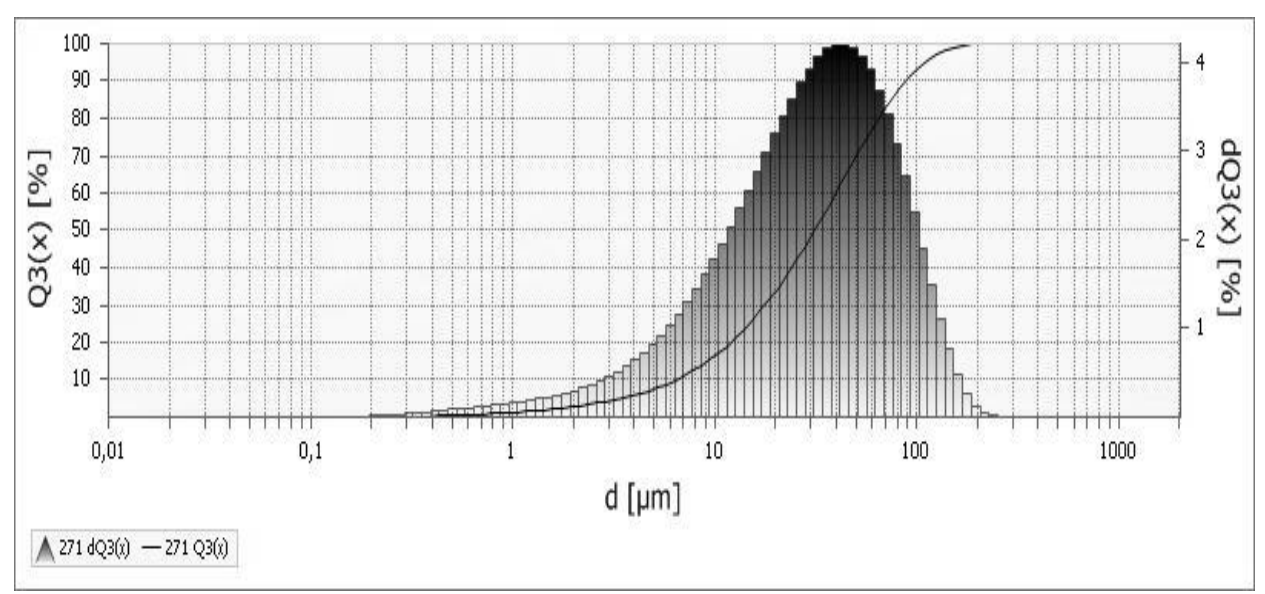

Figura 1: Granulometria do Arenito Zeolítico Calcinado AZ2-3.

\subsubsection{Análise mineralógica dos Arenitos Zeolíticos}

As Figuras 2a e b apresentam os difratogramas das amostras de arenito zeolítico "in natura" (AZ2) e calcinado a $500^{\circ} \mathrm{C}(\mathrm{AZ2}-3)$, respectivamente. A ativação térmica a $500^{\circ} \mathrm{C}$ ocasionou mudanças nas estruturas dos minerais que constituem o arenito zeolítico. Na amostra "in natura", os principais minerais identificados foram a esmectita, o quartzo e a zeólita do tipo estilbita, enquanto que na amostra calcinada, além da presença do quartzo, constataram-se outros minerais diferentes dos originais encontrados na amostra "in natura". Uma esmectita com estrutura cristalina diferente da encontrada na amostra "in natura" e uma zeólita que não pode ser identificada pelos padrões do ICDD-PDF foram formadas após a calcinação. A ativação térmica acarretou em perdas parciais da água presente nas cavidades e na estrutura cristalina da estilbita, além das hidroxilas da esmectita, conforme será discutido na análise térmica, ocasionando mudanças nos arranjos estruturais desses aluminossilicatos originais a ponto de transformá-los em outros minerais.

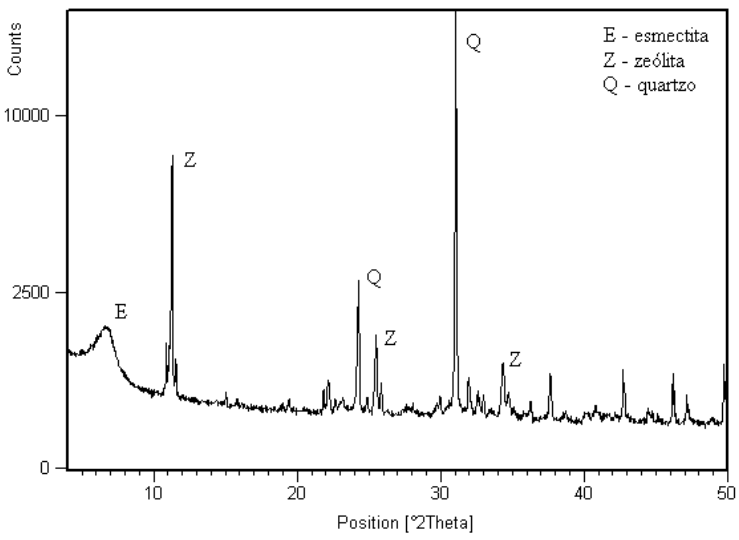

a - Arenito zeolítico AZ2 in natura

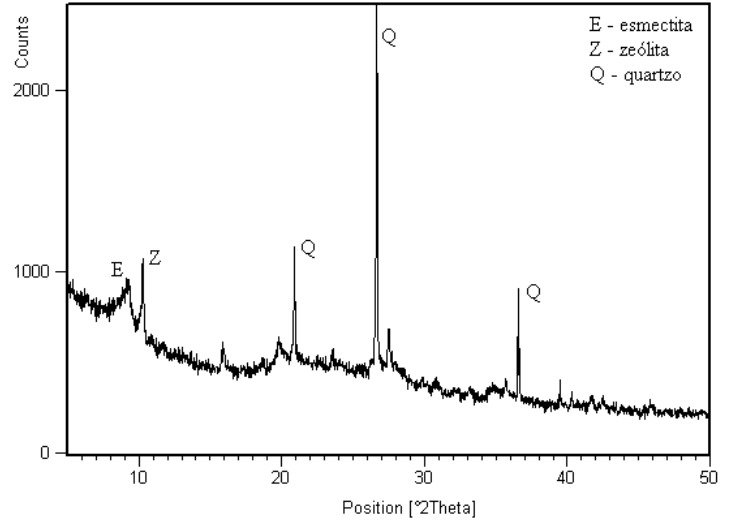

b - Arenito zeolítico AZ2-3

Figura 2: Difração do Arenito Zeolítico.

As análises térmicas (ATD-ATG) dos arenitos "in natura" (AZ2) e calcinado a $500^{\circ} \mathrm{C}$ (AZ2-3) são mostradas nas Figuras 3 a e 3b, respectivamente. No termograma do arenito "in natura" (AZ2), o primeiro evento 
PICANÇO, M.S.; ANGÉLICA, R.S.; BARATA, M.S. revista Matéria, v.19, n.02, pp. 68-80, 2014.

térmico ocorre no intervalo de temperatura entre $40^{\circ} \mathrm{C}$ e $129^{\circ} \mathrm{C}$, que corresponde a uma perda de massa de aproximadamente $6,50 \%$, no qual há um pico endotérmico a $59^{\circ} \mathrm{C}$. Isto se deve a uma rápida perda de umidade superficial, de fases gasosas adsorvidas na superfície e nos nanoporos das amostras, da água nos vazios da estrutura da estilbita e, principalmente, da perda de água interlamelar da esmectita. Entre 129 e $194^{\circ} \mathrm{C}$, a curva da ATG indica uma perda de massa de 3,50 a 3,70\% e na ATD ocorre um pico endotérmico intenso a $159^{\circ} \mathrm{C}$, que retrata a continuação da perda da água que preenche os canais e cavidades da estilbita. A partir de $200^{\circ} \mathrm{C}$ ocorre uma perda de massa de $7,80 \%$, que se atribui em grande parte à perda da água de constituição da estrutura cristalina da estilbita e, em menor proporção, a perda das hidroxilas da esmectita. Na temperatura de $847^{\circ} \mathrm{C}$ na amostra $\mathrm{AZ2}$ ocorreu um pico endotérmico devido à destruição do retículo cristalino da esmectita.

Na amostra calcinada, AZ2-3, a perda ao fogo de 4,10\% é semelhante à obtida na análise química. No intervalo entre $40^{\circ}$ e $200^{\circ} \mathrm{C}$ ocorre uma perda de massa de aproximadamente $2 \%$, atribuída às perdas da água residual nos vazios da estrutura da nova fase zeolítica formada e da água interlamelar da esmectita. A partir de $200^{\circ} \mathrm{C}$ ocorre à perda do restante da água que constitui a estrutura cristalina da nova zeólita, que corresponde a uma perda de massa de aproximadamente $2 \%$.
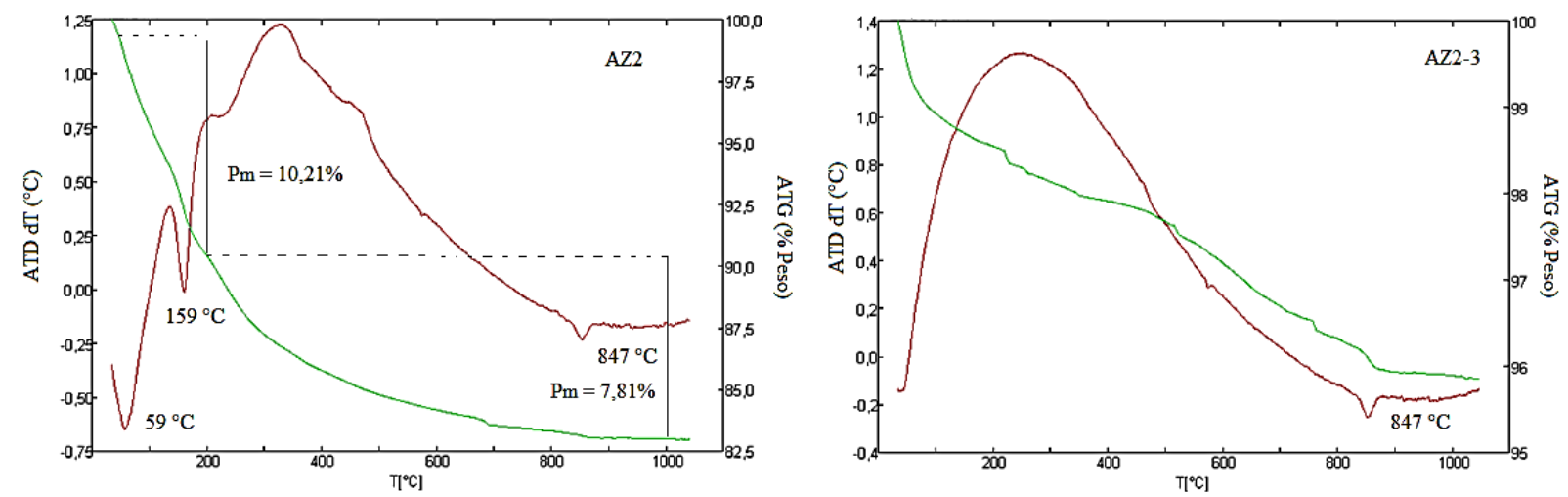

Figura 3: ATD/ATG do arenito.

\subsection{Análise mineralógica das pastas hidratadas}

A Figura 4 mostra as análises térmicas (ATD-TG) aos 07 dias de hidratação das pastas de referência (somente cimento Portland CPIS) e com substituição de 10, 20 e 30\% de cimento Portland CPI-S por arenito zeolítico calcinado (AZ2-3). A Figura 5 mostra o detalhe da ATD no intervalo de temperatura de ocorrência da desidroxilação da portlandita. A Tabela 2 compara os resultados das áreas dos picos correspondentes a efetiva desidroxilação da portlandita nas pastas, com e sem arenito zeolítico, com as áreas teóricas correspondentes ao efeito de diluição da substituição de cimento Portland pela pozolana e deduz o percentual de portlandita efetivamente consumida. A Figura 6 a mostra o espectro de raio-x das pastas hidratadas com e sem arenito zeolítico. De forma análoga à ATD, a Figura 6 b mostra o detalhe do pico de maior intensidade da portlandita gerado nas pastas de cimento Portland, com e sem arenito zeolítico. 
PICANÇO, M.S.; ANGÉLICA, R.S.; BARATA, M.S. revista Matéria, v.19, n.02, pp. 68-80, 2014.

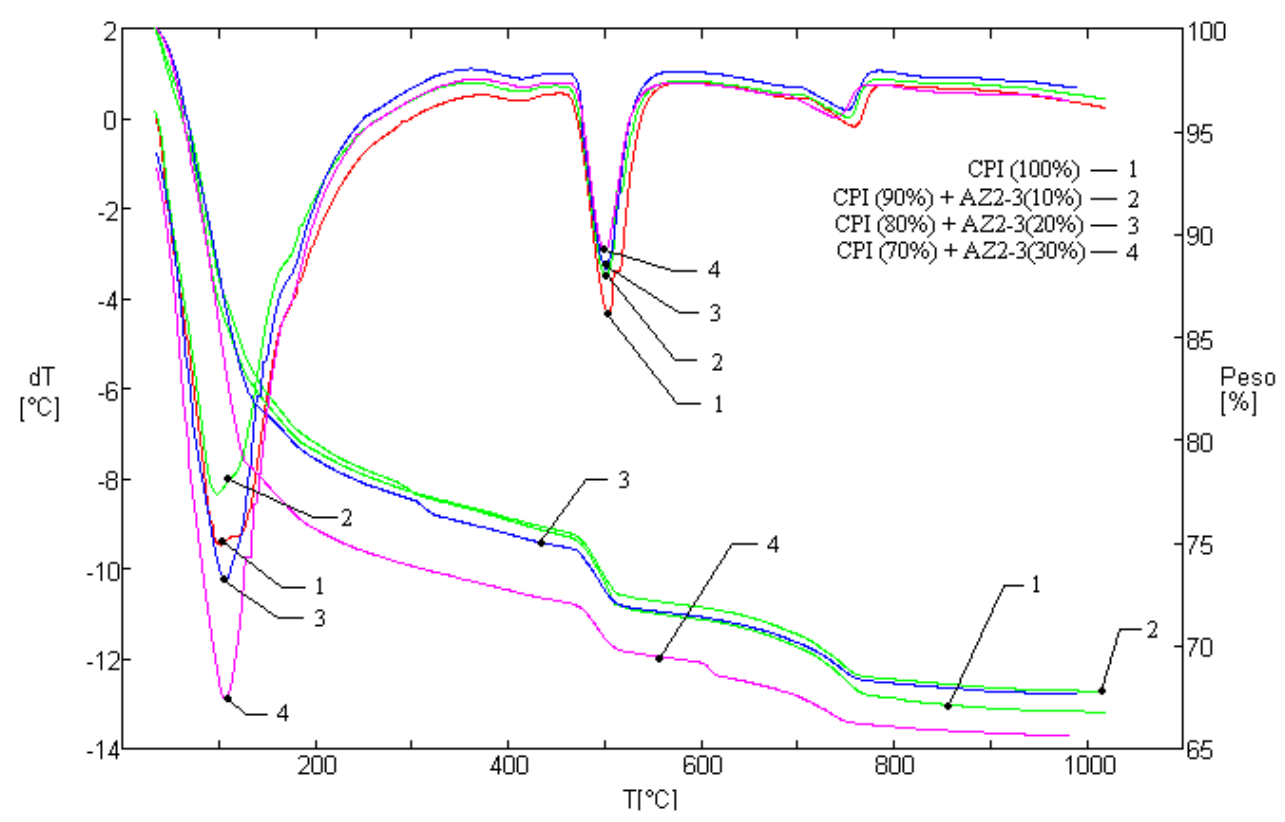

Figura 4 - ATD/ATG das Pastas aos 07 dias de cura.

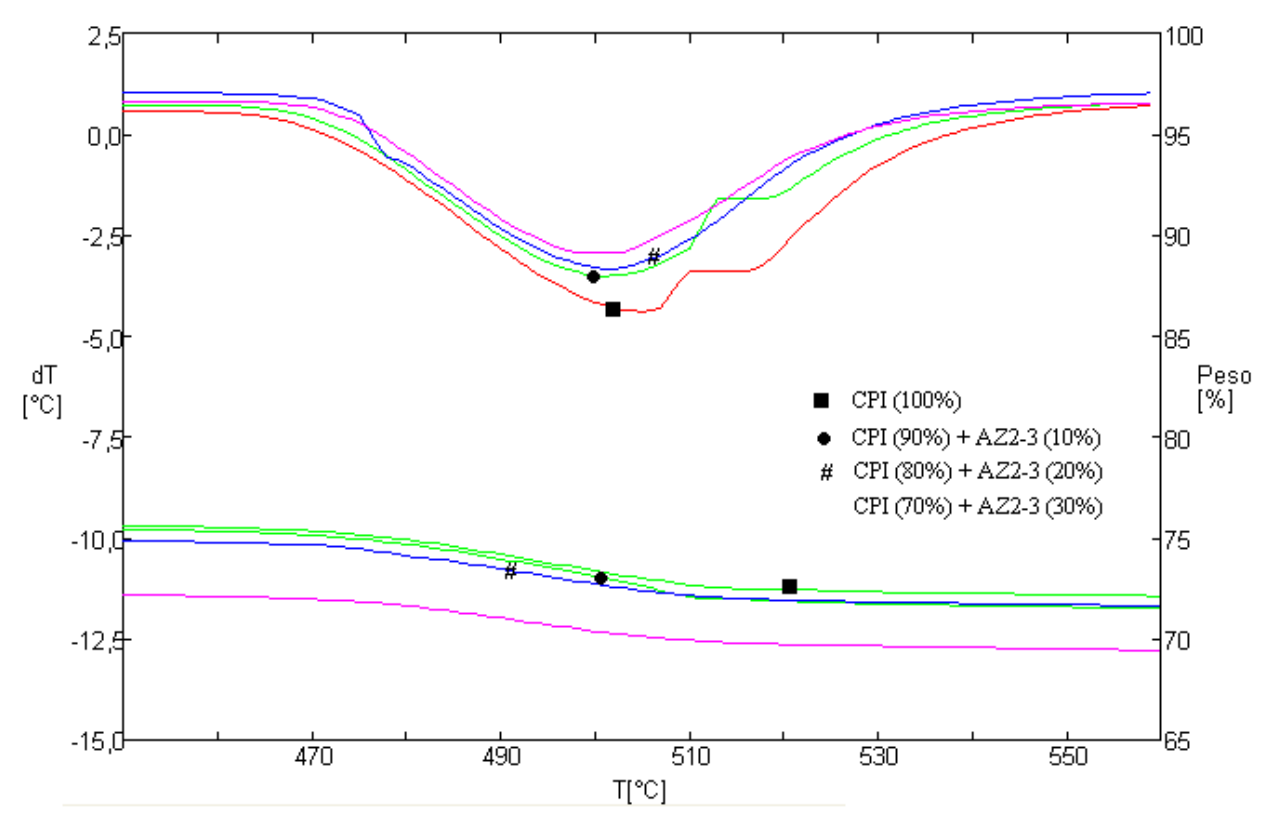

Figura 5: Detalhe da ATD/ATG das Pastas aos 07 dias de cura no intervalo entre 459 e $558^{\circ} \mathrm{C}$.

Tabela 2: Cálculo do consumo de $\mathrm{CaOH} 2$ pela pozolana aos 07 dias.

\begin{tabular}{lccc}
\hline AMOSTRAS & $\begin{array}{c}\text { Área efetiva de } \\
\text { desidroxilação } \\
\text { da portlandita } \\
\text { (A) }\end{array}$ & $\begin{array}{c}\text { Área teórica de Ca- } \\
\mathrm{OH}_{2} \text { levando em } \\
\text { conta o efeito de } \\
\text { diluição } \\
\text { (B) }\end{array}$ & $\begin{array}{c}\text { Diferença (B) - (A) } \\
\mathrm{CaOH}_{2} \text { consumido pela pozolana }\end{array}$ \\
\hline CPI (100\%) & 21,85 & - & - \\
CPI (90\%)+ AZ2-3 (10\%) & 18,36 & 19,67 & 1,31 \\
CPI (80\%)+ AZ2-3 (20\%) & 16,89 & 17,48 & 0,59
\end{tabular}


PICANÇO, M.S.; ANGÉLICA, R.S.; BARATA, M.S. revista Matéria, v.19, n.02, pp. 68-80, 2014. \begin{tabular}{llrl}
$\mathrm{CPI}(70 \%)+\mathrm{AZ2}-3(30 \%)$ & 14,75 & 15,30 & 0,55 \\
\hline
\end{tabular}

As fases hidratadas identificadas na ATD comum a todas as pastas foram o C-S-H $\left(112^{\circ} \mathrm{C}\right)$, a portlandita $\left(503^{\circ} \mathrm{C}\right)$ e a calcita $\left(759^{\circ}\right)$. Nas pastas com o arenito zeolítico observa-se um pico entre $150^{\circ} \mathrm{C}$ e $200^{\circ} \mathrm{C}$. Em razão da presença do alumínio no arenito zeolítico, acredita-se que seja a gehlenita hidratada (C2 ASH8). Devido a baixa cristalinidade desta fase, somente pode ser identificada na ATD de forma mais pronunciada para o percentual de substituição de $30 \%$. Esta afirmação baseia-se nas conclusões de alguns pesquisadores que identificaram a preferencia da formação da gehlenita hidratada ao invés do carboaluminato de cálcio hidratado (C4AH13) quando há a presença de álcalis no sistema metacaulinita/portlandita/água [12]. O arenito zeolítico empregado nas pastas de cimento Portland desta pesquisa possui um teor de álcalis não desprezível. Além disto, a gehlenita hidratada é uma fase de baixa cristalinidade, de difícil detecção na DRX, sendo possível sua identificação para idades superiores a 180 dias e a partir de incorporações de $25 \%$ de metacaulinita, que é uma pozolana com alto teor de alumínio [13].

Outro ponto a ser destacado é a quantidade de portlandita presente nas diferentes pastas. Para se avaliar a efetiva capacidade da pozolana em consumir a portlandita é necessário estimar o conteúdo do mesmo levando em consideração o efeito de diluição do cimento em decorrência da sua substituição pela pozolana para cada teor estudado e subtraí-lo do valor de portlandita determinado na ATD, conforme mostra Tabela 2. Os resultados demonstraram que aos 07 dias de hidratação o maior consumo de hidróxido de cálcio ocorreu para o percentual de $10 \%$ de substituição da pozolana por cimento, enquanto que para teores mais elevados de incorporação, como 20 e $30 \%$ de pozolana, menores quantidades de portlandita são combinadas com a pozolana. Isto se deve a baixa reatividade desta pozolana, que combina lentamente com a portlandita. Por esta razão, o menor percentual de pozolana foi capaz de consumir mais rapidamente a portlandita gerada na hidratação do cimento aos 07 dias do que os maiores percentuais de 20 e $30 \%$, que consumirão a portlandita no maior espaço de tempo, provavelmente para idades mais avançadas. De acordo com [1], pozolanas de menor reatividade quando incorporadas em percentuais elevados como de 20 e $30 \%$ irão consumir a portlandita para formação de C-S-H de modo a repercutir de forma significativa na resistência e na redução da permeabilidade a partir de 60 dias. Portanto, acredita-se que a incorporação de percentuais maiores de arenito zeolítico calcinado, entre 20 e $30 \%$, irão proporcionar efeitos positivos na resistência somente a partir de idades mais avançadas.

Estes resultados também foram corroborados na difração de raio-x das pastas hidratadas. Na Figura 6b, através da avaliação da intensidade do pico de maior intensidade da portlandita, constatou-se que o maior consumo da portlandita ocorreu para o percentual de $10 \%$ de incorporação do AZ2-3, tendo em vista a menor intensidade do pico, que se traduz em uma menor quantidade desta fase mineral na pasta aos 07 dias.
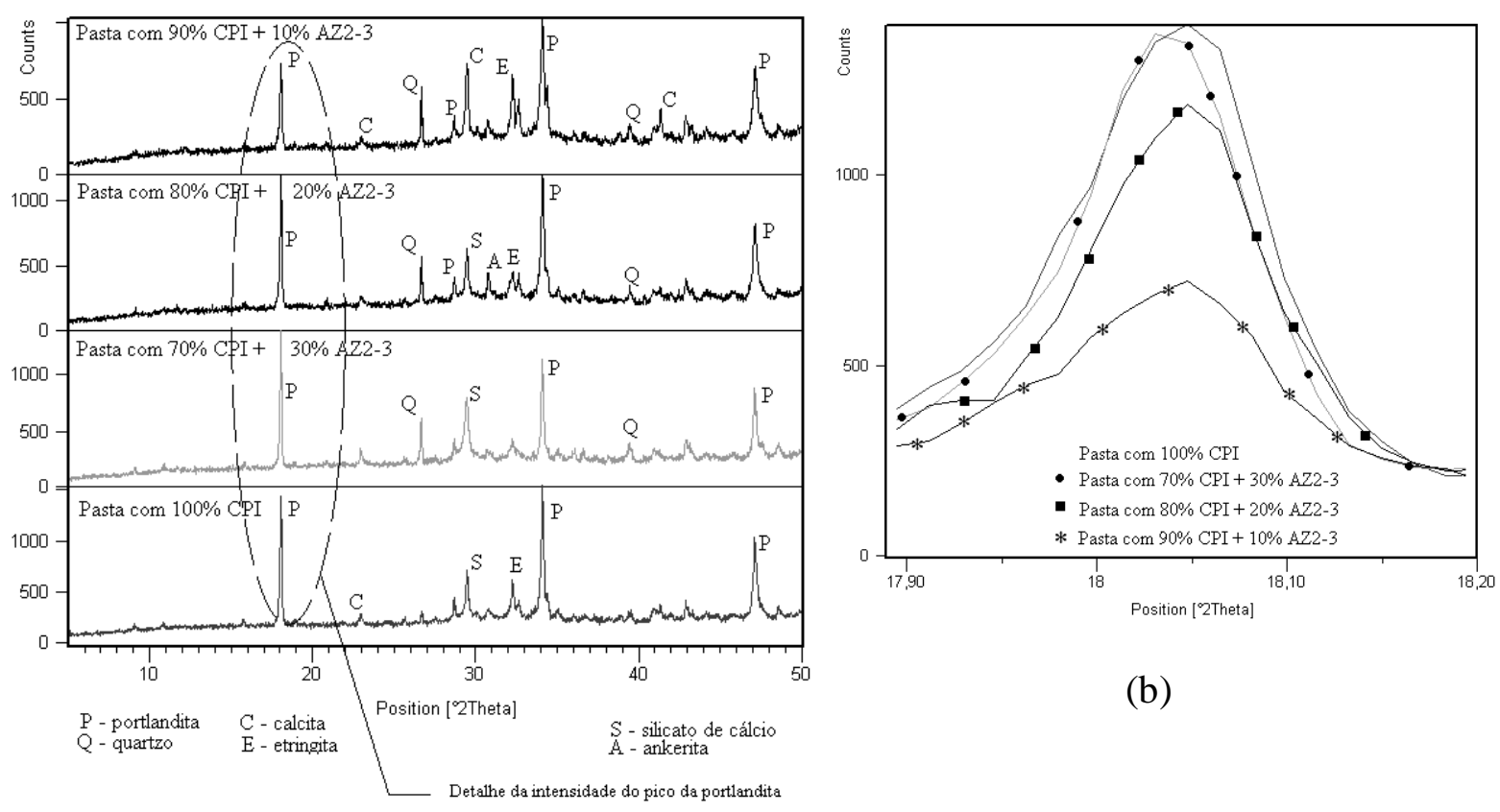

(b)

(a)

Figura 6: Difratogramas de raios- $X$ das pastas hidratadas com 07 dias: (a) Pastas com CPI e AZ2-3; (b) Detalhe do pri- 
PICANÇO, M.S.; ANGÉLICA, R.S.; BARATA, M.S. revista Matéria, v.19, n.02, pp. 68-80, 2014.

meiro pico da portlandita $(\mathrm{d}=4,92 \AA)$ das pastas com CPI e AZ2-3

\subsubsection{Calorimetria das Pastas Hidratadas}

As curvas de evolução de calor das pastas com e sem arenito são mostradas na Figura 7. As quantidades de calor total gerada pelas pastas com arenito variaram entre 50,19 mw.h/g a 61,67 mw.h/g, dependendo do teor de substituição do cimento Portland pelo arenito, enquanto que a da pasta de referência foi de 70,37 mw.h/g. A incorporação do arenito zeolítico calcinado às pastas de cimento Portland ocasionou a redução na quantidade de calor gerada pelas reações de hidratação em razão da menor reatividade destas adições, o que fez com que o efeito de diluição do cimento fosse preponderante sobre o calor gerado pela reação pozolânica. A pasta de cimento Portland com 30\% de AZ2-3 apresentou menor valor de calor de hidratação, 50,19mw.h/g, em comparação aos 70,37mw.h/g gerados pela pasta de referência, constituída apenas de cimento Portland. Este fato é extremamente positivo em termos de durabilidade do material, pois quanto menor o calor liberado pelas reações de hidratação e pozolânica, menor a probabilidade de ocorrência de fissuras.

A incorporação do arenito zeolítico calcinado ocasionou a intensificação e antecipação do segundo pico exotérmico ocorrido às 20 horas na pasta de referência para às 17 horas de hidratação nas pastas com pozolanas. Este pico corresponde à conversão parcial da etringita (trissulfoaluminato de cálcio hidratado) em monossulfoaluminato de cálcio hidratado. A conversão é uma reação inerente da hidratação do cimento Portland. Contudo, foi acelerada pela presença dos aluminossilicatos presentes nos arenitos (estilbita e esmectita). $\mathrm{O}$ aumento da concentração de aluminatos na solução da pasta torna a etringita instável, convertendo-a em monossulfoaluminato de cálcio hidratado, além de antecipar a reação de conversão.

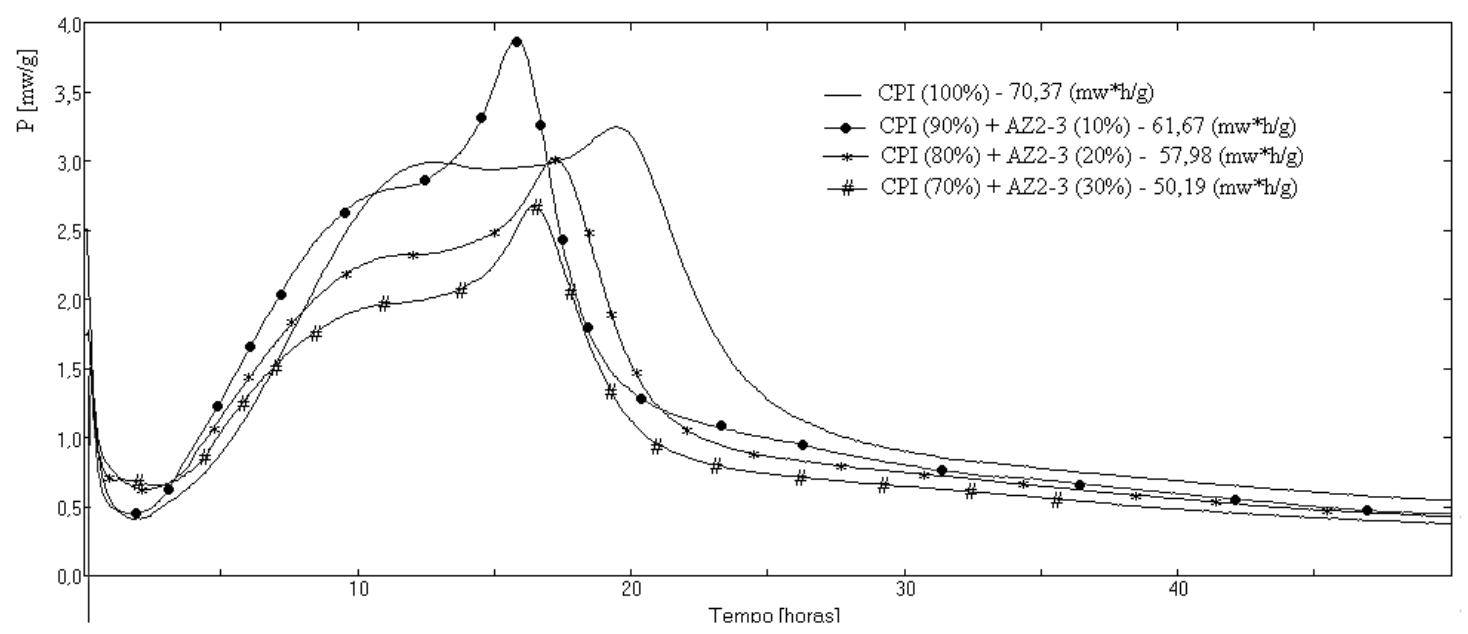

Figura 7: Curvas de evolução de calor das pastas com e sem incorporação de AZ23.

\subsection{Avaliação do comportamento mecânico}

\subsection{Resistência à Compressão Simples}

Nas Tabelas 3 e 4 e Figura 8 são mostrados os resultados do ensaio de resistência à compressão das argamassas de referência e com 10, 20 e 30\% de arenito zeolítico AZ2-3. Em todas as argamassas constatou-se uma evolução da resistência de 7 para 28 dias. As argamassas com pozolanas, independentemente do teor de incorporação, apresentaram resistências inferiores a da argamassa de referência para ambas as idades. Isto se deve ao fato do arenito ser uma pozolana de baixa reatividade, cuja capacidade de reagir com a portlandita é mais lenta. Entretanto, para o teor de $10 \%$ de incorporação, a argamassa com arenito já alcançou resistências satisfatórias do ponto de vista de utilização comercial.

Com relação aos percentuais de incorporação de arenito, a argamassa com $10 \%$ foi a que apresentou a maior resistência em relação ao demais percentuais de 20 e $30 \%$. Neste percentual não tão elevado de incorporação, a pozolana é capaz de converter a portlandita em C-S-H mais rapidamente, conforme pode ser constatado nas análises térmicas e de difração de raio-x. Pelo fato do arenito ser uma pozolana de baixa reatividade, acredita-se que as argamassas com teores de 20 e 30\% de incorporação continuarão a apresentar desenvolvimento de resistência ao longo de tempo. Trabalhos anteriores constataram que as zeólitas de baixa reati- 
PICANÇO, M.S.; ANGÉLICA, R.S.; BARATA, M.S. revista Matéria, v.19, n.02, pp. 68-80, 2014.

vidade são capazes de combinar com a portlandita até a idade de 365 dias [14]. Diante, parte da hipótese que a argamassa com teor de $10 \%$ de arenito possa suplantar a de referência para idades mais avançadas.

Tabela 3: Resistência à Compressão aos 7 dias.

\begin{tabular}{ccccc}
\hline \multirow{2}{*}{ Amostras } & \multicolumn{2}{c}{} & \multirow{2}{*}{ Média } \\
& \multicolumn{2}{l}{ Resistência a Compressão simples (MPa) } & \\
\cline { 2 - 4 } & 1 & 2 & 3 & \\
\hline Argamassa de ref. & 33,40 & 32,60 & 29,90 & 31,97 \\
\hline CPI $(90 \%)+$ AZ23 (10\%) & 30,60 & 29,70 & 31,20 & $\mathbf{3 0 , 5 0}$ \\
\hline CPI $(80 \%)+$ AZ23 (20\%) & 18,70 & 21,20 & 19,20 & 19,70 \\
\hline CPI $(70 \%)+$ AZ23 (30\%) & 16,00 & 15,60 & 15,80 & 15,80 \\
\hline
\end{tabular}

Tabela 4: Resistência à Compressão aos 28 dias.

\begin{tabular}{ccccc} 
Amostras & \multicolumn{2}{c}{ Resistência a Compressão simples (MPa) } & Média \\
\cline { 2 - 4 } & 1 & 2 & 3 & \\
\hline Argamassa de ref. & 37,50 & 36,20 & 38,20 & 37,30 \\
\hline CPI $(90 \%)+$ AZ23 (10\%) & 32,90 & 32,30 & 32,10 & $\mathbf{3 2 , 4 4}$ \\
\hline CPI $(80 \%)+$ AZ23 (20\%) & 22,10 & 23,60 & 22,40 & 22,70 \\
\hline CPI $(70 \%)+$ AZ23 (30\%) & 17,70 & 18,60 & 19,00 & 18,43 \\
\hline
\end{tabular}

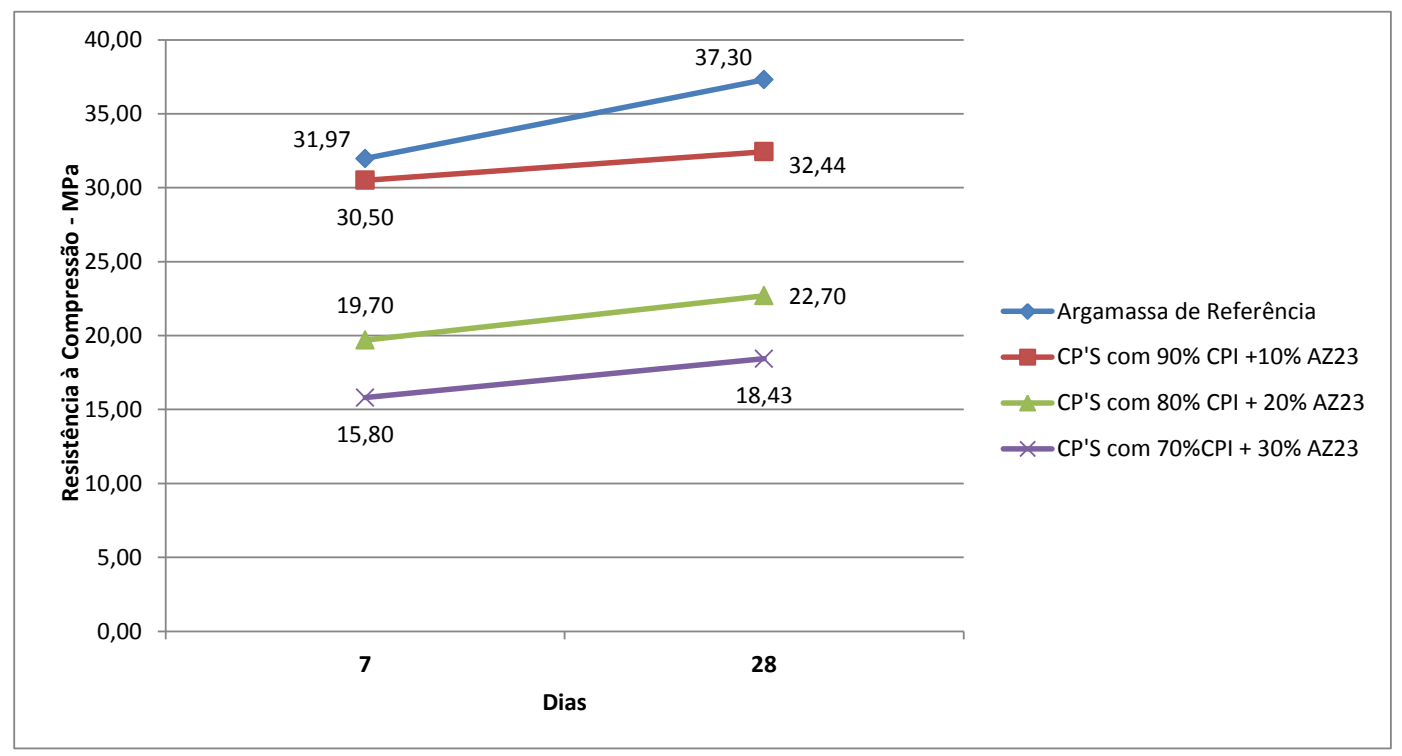

Figura 8: Resistência à Compressão das argamassas com e sem AZ2-3.

A título de comparação são mostrados na Tabela 5 valores de atividade pozolânica de outras adições minerais com alto teor de alumínio. Apesar do arenito zeolítico apresentar a menor reatividade em comparação as demais pozolanas, ainda assim atinge o mínimo de $75 \%$ exigido para que um material seja empregado comercialmente como pozolana. Estudos complementares sobre resistência à compressão para idade superiores, resistência à carbonatação e à corrosão das armaduras, retração por secagem e reação álcali-agregado são necessários para avaliar a eficiência desta pozolana com vista a seu emprego na construção civil e em obras de infraestrutura. 
PICANÇO, M.S.; ANGÉLICA, R.S.; BARATA, M.S. revista Matéria, v.19, n.02, pp. 68-80, 2014.

Tabela 5: Comparação de resultados entre arenito zeolítico e estudos anteriores.

\begin{tabular}{ccc}
\hline Amostra & Autor & IAP CP $(\%)$ \\
\hline AZ2-3 (arenito zeolítico) & PICANCO et al., 2012 [7] & 74,50 \\
\hline TM -100 (arenito opalino) & MONTANHEIRO et al., 2002 [8] & 79,00 \\
TM - 101 (arenito opalino) & MONTANHEIRO et al., 2002 [8] & 90,00 \\
\hline RCC90 (metacaulim) & BARATA 2007 [16] & 95,20 \\
\hline
\end{tabular}

*IAP CP (\%) - Índice de atividade pozolânica com cimento Portland.

\section{CONCLUSÕES}

$\mathrm{O}$ arenito zeolítico quando ativado termicamente a $500^{\circ} \mathrm{C}$ tem sua estrutura cristalina alterada. A estilbita e a esmectita existentes originalmente são transformadas em outras fases. A estilbita transformou-se em outra zeólita cujo padrão cristalográfico não foi possível identificar nas fichas do ICDD-PDF.

$\mathrm{O}$ arenito zeolítico AZ2-3 calcinado a $500^{\circ} \mathrm{C}$ apresentou uma baixa atividade pozolânica, tendo em vista a lenta taxa de desenvolvimento da reação pozolânica. Aos 07 dias, grande parte do hidróxido de cálcio ainda estava presente nas pastas. Este efeito repercute de forma mais significativo para os teores mais elevados de incorporação como 20 e $30 \%$, pois a capacidade de reação da pozolana é incipiente para consumir o hidróxido de cálcio gerado pela hidratação do cimento, principalmente para as idades mais precoces como 7 e 28 dias.

Isto se reflete no comportamento mecânico das argamassas. As resistências das misturas com arenito zeolítico calcinado não ultrapassaram as da argamassa de referência aos 28 dias. No caso das argamassas com percentuais elevados de incorporação como 20 e 30\%, as resistências foram muito inferiores em relação à da argamassa de referencia. Contudo, para teores menores como $10 \%$ a argamassa já apresentou resistência de $32 \mathrm{MPa}$, considerada satisfatória para uso na indústria da construção. $\mathrm{O}$ arenito zeolítico caracteriza-se como uma pozolana de baixa reatividade, por esta razão acredita-se que os teores mais elevados de incorporação como 20 e 30\% alcancem resistências mais elevadas para idades mais avançadas como 180 a 365 dias.

Estudos mais aprofundados sobre as propriedades do concreto para idades mais avançadas são importantes para avaliar o efeito do arenito zeolítico sobre a resistência e a durabilidade do concreto com vistas a emprega-lo como uma pozolana de emprego comercial, principalmente nas obras de infraestrutura como barragens, diques, canais, entre outras, na qual a durabilidade é um requisito importante.

\section{AGRADECIMENTOS}

Ao CNPq, pela bolsa concessão de bolsa de doutorado ao primeiro autor e bolsa de produtividade em pesquisa ao segundo (Processos 304.566/2007-1 e 303.871/2010-5). A CPRM pelo auxílio nos trabalhos de campo e coleta do material estudado. Esse trabalho contou com recursos financeiros do Projeto Minomat: Dos Minerais Aos Novos Materiais - Caracterização de matérias-primas e rejeitos minerais, modificação, síntese e aplicações industriais. Agência/Financiador: EDITAL N ${ }^{\circ}$ 02/2007 Seleção de Projetos de Pesquisa do Programa de Apoio a Núcleos de Excelência (PRONEX), da Fundação de Amparo à Pesquisa do Estado do Pará (FAPESPA) e do CNPq, sob a coordenação do Prof. Dr. Marcondes Lima da Costa

\section{REFERÊNCIAS BIBLIOGRÁFICAS}

[1] MEHTA, K., MONTEIRO, J.P., Concreto: Estrutura, Propriedade e Materiais, São Paulo, Editora Pini, 1994.

[2] ZAMPIERI, V.A., Cimento Portland Aditivado com Pozolanas de Argilas Calcinadas: Fabricação, Hidratação e Desempenho Mecânico, Tese de D.Sc, Universidade de São Paulo, São Paulo, SP, Brasil, 1993.

[3] PERRAKI, T.H., KAKALI, G., KONTOLEON, F., "The effect of natural zeolites on the early hydration of Portland cement”, Microporous and Mesoporous Materials, v 61, pp. 205-212, Jul. 2003.

[4] REZENDE, N.G.A.M., ANGÉLICA, R.S, “Sedimentary Zeolites in Brasil”, Mineralogica et Petrografica Acta, v 42, pp.71-82. 1999.

[5] MUSTELIER, J.L.C., Geología, Caracterización y Aplicaciones de las rocas zeolíticas del complejo volcánico de Cabo de Gata (Almería), Tese de D.Sc, Escuela Técnica Superior de Ingenieros de Minas, Madrid, España, 2008.

[6] PICANÇO, M.S., ANGÉLICA, R.S., BARATA, M.S., Arenito Zeolítico da região Nordeste do Brasil com propriedades pozolânicas, 2011. 
PICANÇO, M.S.; ANGÉLICA, R.S.; BARATA, M.S. revista Matéria, v.19, n.02, pp. 68-80, 2014.

[7] PICANÇO, M. S., ANGÉliCA, R. S., BARATA, M. S., “Atividade Pozolânica de Arenito Zeolítico da Região Nordeste do Brasil”, Revista Escola de Minas, v. 65, n 2, pp 161-168, Abr-Jun. 2012.

[8] MONTANHEIRO, T.J., YAMAMOTO, J.K., KIHARA, Y., "Características e propriedades pozolânicas de arenitos opalinos da Serra de Itaqueri, SP”, Revista do Instituto Geológico, v. 23, n. 1, pp. 13-24, Jun. 2002.

[9] ANGÉLICA, R.S., REZENDE, N.G.A.M., COSTA, M.L.,'Estudos mineralógicos e geoquímicos preliminares da ocorrência de zeólitas em sedimentos mesozóicos da bacia do Parnaíba, Brasil.” In: V Congresso Brasileiro de Geoquímica, Niterói, RJ, 1995.

[10] MEIER, W. M., Molecular Sieves, Soc. Chem. Ind., London, 10 p.

[11] ASSOCIAÇÃO BRASILEIRA DE NORMAS TÉCNICAS - ABNT - NBR 12653: Materiais pozolânicos: Especificação. Rio de Janeiro, 2012.

[12] FRIAS, M., CABRERA, J., "Influence of MK on the reaction kinetics in MK/lime and MK blended cement system at $20^{\circ} \mathrm{C} "$, Cement and Concrete Research, v. 31, pp. 519-527, 2001.

[13] AMBROISE, J., MAXIMILIEN, S., PERA, J., "Properties of metakaolin blended cements", Advanced Cement Based Materials, v.1, n.4, pp.161-168, 1994.

[14] LILKOV, V., PETROV, O., PETKOVA, V., et al, "Study of the pozzolanic actity and hydration products of cement pastes with addition of natural zeolites", Clay Minerals, v 46, pp. 241-250, Jan. 2011.

[15] BARATA, M.S., Aproveitamento dos resíduos cauliníticos das indústrias de beneficiamento de caulim da região amazónica como matéria-prima para a fabricação de um material de construção (pozolanas), Tese de D.Sc, Universidade Federal do Pará, Belém, PA, Brasil, 2007. 